\title{
Phenazine Production by Pseudomonas sp. LBUM223 Contributes to the Biological Control of Potato Common Scab
}

\author{
Tanya Arseneault, Claudia Goyer, and Martin Filion
}

First and third authors: Université de Moncton, Department of Biology, Moncton, NB, Canada; and second author: Potato Research Center, Agriculture and Agri-Food Canada, Fredericton, NB, Canada. Accepted for publication 28 April 2013.

\section{ABSTRACT}

Arseneault, T., Goyer, C., and Filion, M. 2013. Phenazine production by Pseudomonas sp. LBUM223 contributes to the biological control of potato common scab. Phytopathology 103:995-1000.

Common scab of potato is mainly caused by Streptomyces scabies. Currently, no method can efficiently control this economically important disease. We have previously determined that Pseudomonas sp. LBUM223 exhibits antagonistic properties toward $S$. scabies under in vitro conditions. Inhibition was mainly attributed to phenazine-1-carboxylic acid (PCA) production because an isogenic mutant of LBUM223 (phzC-), not producing PCA, was incapable of significantly reducing $S$. scabies growth. In order to understand the impact of PCA production by LBUM223 in controlling common scab under soil conditions, pot experi- ments were performed to determine its effect on (i) reducing scab symptoms development, (ii) $S$. scabies population dynamics, and (iii) txtA expression in S. scabies, a key gene involved in thaxtomin A biosynthesis and required for pathogenesis. Symptoms were significantly reduced following inoculation with LBUM223 but not its mutant. Surprisingly, pathogen populations increased in the geocaulosphere in the presence of both wild-type and mutant strains of LBUM223; however, significant repression of txtA expression in S. scabies was only observed in the presence of PCA-producing LBUM223, not its mutant. These results suggest that, under soil conditions, PCA production by LBUM223 does not control common scab development by antibiosis but, instead, reduces $S$. scabies thaxtomin A production in the geocaulosphere, leading to reduced virulence.
Common scab is a bacterial infection of potato (Solanum tuberosum L.) primarily caused by Streptomyces scabies, which directly attacks actively growing tubers by causing necrotic lesions that reduce potato marketability (16). No method alone can currently eradicate this disease, and cultivar resistance has not yet been fully obtained, suggesting that it is not a simply inherited trait (10). The necrotic lesions, or scabs, found on tuber surfaces colonized by $S$. scabies are due to its production of thaxtomins (17). Thaxtomin A, the thaxtomin most widely secreted by $S$. scabies, is a nitrated dipeptide composed of tryptophan and phenylalanine. It inhibits cellulose synthesis in expanding plant tissues, resulting in weak cell walls (7). Thaxtomin A is produced by enzymes encoded by the genes NOS, txtA, txtB, and txtC grouped on a mobile pathogenicity island (PAI) and is regulated by the TxtR protein, which is activated by the binding of the cellulose degradation products cellobiose (21) or cellotriose (13) in the presence of suberin (19). TxtA and TxtB are responsible for the production of the $\mathrm{N}$-methylated cyclic dipeptide base structure of thaxtomin A, while TxtC, a P450 monooxygenase, subsequently hydroxylates the molecule (11). A recent study has shown that thaxtomin A production correlates with the number of txtA and $t x t C$ transcripts detected by reverse-transcription quantitative polymerase chain reaction (RT-qPCR) and that thaxtomin A accumulation closely follows $t x t A$ and $t x t C$ gene expression (28).

Many of the antagonistic microorganisms inhabiting diseasesuppressive soils (8) have been shown to repress plant pathogens' presence by secreting antimicrobial compounds (32), a concept known as antibiosis. Fluorescent Pseudomonas spp. have repeatedly been shown to be useful biocontrol agents, in part due to their capacity to produce various antimicrobial compounds, in-

Corresponding author: M. Filion; E-mail address: martin.filion@umoncton.ca

http://dx.doi.org/10.1094/PHYTO-01-13-0022-R

(c) 2013 The American Phytopathological Society cluding phenazines (5). Fluorescent Pseudomonas spp. have been proven present on tuber surfaces as potent antagonists against different potato pathogens (29), as well as being of significant aid in promoting tuber growth (15). Thus, inoculation of the potato rhizosphere (the soil in close contact with roots) and geocaulosphere (the soil in close contact with potato tubers) with selected antimicrobial-producing fluorescent Pseudomonas spp. in the aim of controlling common scab of potato appears to be an interesting biocontrol strategy.

In vitro confrontational assays previously performed in our laboratory have revealed that a fluorescent Pseudomonas sp. strain, LBUM223, can significantly repress the growth of $S$. scabies under in vitro conditions, and that this control appears linked to its capacity to produce phenazine-1-carboxilic acid (PCA) (26). Indeed, an isogenic mutant ( $p h z C-$ ) deficient in PCA production was incapable of significantly repressing the growth of the pathogen. In the present study, in order to better understand the impact of PCA production by LBUM223 on the biocontrol of common scab under soil conditions, pot experiments were performed to determine its effect on (i) reducing common scab symptom development, (ii) the population dynamics of $S$. scabies in the geocaulosphere and rhizosphere of potato, and (iii) the expression of txtA in S. scabies, a key gene involved in thaxtomin A biosynthesis, which is required for pathogenesis. We also assessed whether the application of wild-type Pseudomonas sp. LBUM223 or its mutant ( $p h z C-$ ) had an effect on overall plant growth.

\section{MATERIALS AND METHODS}

Bacterial strains and growth conditions. Thaxtomin Aproducing S. scabies LBUM848 was isolated from common scab lesions on a potato tuber harvested in Bloomfield, NB, Canada (27). Pseudomonas sp. LBUM223 was previously isolated from the rhizosphere of strawberry plants in Bouctouche, NB, 
Canada (24). An isogenic mutant of LBUM223, LBUM223 $p h z C$-, incapable of producing PCA, was generated and validated as previously described (26). All strains were routinely grown in tryptic soy broth (BD, Franklin Lakes, NJ) with shaking at $25^{\circ} \mathrm{C}$.

Soil and seed preparation. The soil used (sandy loam, pH 6.7) was collected from the Agriculture and Agri-Food Canada S. H. J. Michaud Research Farm (Bouctouche, NB, Canada) and sieved $(4 \mathrm{~mm})$. As a potting soil mix, three parts of soil were mixed with one part of sand and autoclaved twice during two consecutive days at $121^{\circ} \mathrm{C}$ for $1 \mathrm{~h}$ prior to use. Seed tubers ('Kennebec') were kept at room temperature until multiple sprouts had started to appear on each tuber and then cut in 2- to $3-\mathrm{cm}^{2}$ pieces bearing at least one sprout. Tuber pieces were left to heal for 3 days at $15^{\circ} \mathrm{C}$ before planting.

S. scabies and Pseudomonas sp. inocula. The $S$. scabies inoculum was prepared in soil. Soil was placed in trays and autoclaved twice during two consecutive days $\left(121^{\circ} \mathrm{C}\right.$ for $\left.1 \mathrm{~h}\right)$ and left for 2 days prior to use. Say solution (20 $\mathrm{g}$ of sucrose, $1.2 \mathrm{~g}$ of L-Asp, $0.6 \mathrm{~g}$ of $\mathrm{K}_{2} \mathrm{HPO}_{4}$, and $10 \mathrm{~g}$ of yeast extract [BD] per liter) was added to the trays at one-sixth of total soil volume and the trays were again autoclaved using the same conditions. A well-grown culture (for 4 days at $25^{\circ} \mathrm{C}$ with shaking at $200 \mathrm{rpm}$ ) of S. scabies was then used to inoculate the soil, at a ratio of 1:20. A negative control was also prepared using the autoclaved soil without adding $S$. scabies. The soil inocula (with $S$. scabies or negative control) were shaken vigorously and regularly for an incubation period of 14 days at $30^{\circ} \mathrm{C}$. S. scabies concentration (CFU per gram of soil) was estimated by standard microbiological plating on tryptic soy agar.

For Pseudomonas sp. LBUM223 wild-type and isogenic mutant $p h z C$ - treatments, liquid inocula were prepared by growing each respective strain at $25^{\circ} \mathrm{C}$ for 3 days with shaking at $250 \mathrm{rpm}$. Populations were estimated using spectrophotometer readings $(\lambda=600 \mathrm{~nm})$ and a standard curve.

Growth chamber experiments. The experimental set-up consisted of nine replicates of each of the following treatments: (i) no inoculum (control), (ii) LBUM223, (iii) LBUM223 phzC-, (iv) S. scabies (no antagonist), (v) S. scabies + LBUM223, and (vi) S. scabies + LBUM223 phzC-. The entire experiment was repeated a second time. For pots requiring $S$. scabies, the $S$. scabies soil inoculum was blended with the potting soil mix to obtain $\approx 5 \times 10^{7} \mathrm{CFU} / \mathrm{g}$ of soil, and a total of $1 \mathrm{~kg}$ of soil was added per 6-in. pot. For pots not requiring $S$. scabies, the same amount of negative control soil inoculum was used. For antagonist treatments, tubers were first dipped in a bacterial culture of either LBUM223 or LBUM223 phzC-; then, the rest of the culture was subsequently added to the pot around the seed tuber to obtain a final concentration of $4 \times 10^{7} \mathrm{CFU} / \mathrm{g}$ of soil. Negative controls received the same volume of water. Tubers (one per pot) were planted at a depth of $\approx 5 \mathrm{~cm}$. Pots were placed in the growth chamber (Conviron CMP5000 series; Controlled Environments, Winnipeg, MB, Canada) using a completely randomized design, and were exposed to $16 \mathrm{~h}$ of daylight at $23^{\circ} \mathrm{C}$ and $8 \mathrm{~h}$ of darkness at $18^{\circ} \mathrm{C}$. After 8 weeks, the photoperiod was reduced to $10 \mathrm{~h}$ to favor tuber growth. Plants were watered daily or every other day as needed with $100 \mathrm{ml}$ of tap water and fertilized once most plants had broken soil and again after 3, 7, and 10 weeks with a water-soluble fertilizer (all-purpose fertilizer 20-20-20, N:P:K). Destructive harvesting of three replicates per treatment occurred at 5, 10, and 15 weeks. Shoots, roots, tubers, and rhizosphere and geocaulosphere soil were sampled. At each sampling time, the plants and tubers were shaken to remove loosely adhering soil, and the soil remaining on the roots and the tubers was sampled and labeled as rhizosphere and geocaulosphere, respectively. No tubers were present at week 5 and, consequently, no potato geocaulosphere was harvested at that time. Total plant weight, consisting of shoot and root combined weight without tubers, was determined prior to freezing all soil and plant samples in liquid nitrogen and then storing at $-80^{\circ} \mathrm{C}$. Disease severity was assessed by estimating the percentage of common scab lesion coverage on each harvested tuber. Values were averaged for all tubers originating from the same plant.

Extraction of DNA and RNA from soil. Rhizosphere and geocaulosphere soil samples were lyophilized prior to nucleic acid extractions. DNA was extracted using the UltraClean Soil DNA Isolation Kit (Mobio, Carlsbad, CA) following the manufacturer's instructions, except for the vortex mixing step that was substituted with the use of a FastPrep (QBiogene, MP Biomedicals, Santa Ana, CA) at a speed of $5.5 \mathrm{~ms}^{-1}$ during $45 \mathrm{~s}$. Extracted DNA was diluted 1:10 prior to qPCR analyses. The same samples were also submitted to RNA extraction using the protocol described by Bürgmann (4), using a FastPrep as the homogenizing apparatus and resuspending the final RNA pellet in $100 \mu \mathrm{l}$ of diethylpyrocarbonate (DEPC)-treated water. Resuspended RNA was submitted to a DNAse treatment (TURBO DNA-free, Ambion; Applied Biosystems, Foster City, CA), using $20 \mu \mathrm{l}$ of the provided $10 \times$ buffer, $3 \mu \mathrm{l}$ of enzyme, $100 \mu \mathrm{l}$ of RNA, and $77 \mu \mathrm{l}$ of DEPC-treated water. A $45-\mathrm{min}$ incubation at $37^{\circ} \mathrm{C}$ was done prior to performing a chloroform extraction and the final pellet was resuspended in $50 \mu \mathrm{l}$ of DEPC-treated water. A second DNAse treatment was performed following the manufacturer's instructions (TURBO DNA-free, Ambion; Applied Biosystems), with a second-digest buffer (200 mM Tris-HCl, $100 \mathrm{mM}$ $\mathrm{MgCl}_{2}$, and $5 \mathrm{mM} \mathrm{CaCl}, \mathrm{pH}$ 7.5) and use of the provided inactivation reagent, resulting in a final volume of $65 \mu \mathrm{l}$. Prior to qPCR analyses, $7.9 \mu \mathrm{l}$ of RNA was retro-transcribed using the reverse $t x t A$ primer (26) and the TaqMan Reverse Transcription Reagents Kit (Applied Biosystems).

qPCR and RT-qPCR analysis of $\boldsymbol{t x t} \boldsymbol{A}$. The primers and TaqMan probe targeting $t x t A$ have previously been described (26) and were purchased from Integrated DNA Technologies (Coralville, IA) and Applied Biosystems, respectively. The DNA and cDNA obtained from the rhizosphere and geocaulosphere soil samples were amplified using the TaqMan PCR Core Reagent Kit (Applied Biosystems) and an ABI 7500 RealTime PCR System (Applied Biosystems). Each-25 $\mu \mathrm{l}$ reaction was prepared following the manufacturer's instructions and contained $100 \mathrm{nM}$ TaqMan probe and $200 \mathrm{nM}$ each primer. qPCRs were performed in triplicate and included no-template controls and a standard curve, determined by serial dilutions of a known number of plasmids containing txtA, to obtain absolute gene copy numbers. Plasmid standards were developed as previously described (6).

Statistical analyses. Two-factor analyses of variance (time and treatment) were performed with subsequent Tukey-Kramer adjustment to determine significance $(P<0.05)$. Mixed models were used to include a random factor, which removes variation between different replications of experiments and allows the analysis of both experiments together $(n=6)$. The interaction between factors was verified and, if an interaction occurred, analyses were completed per time point. The absence of an interaction confirmed that the trend observed was the same at all time points, which means that the effect of a particular treatment is true at all times combined. Population and expression data required log transformations to achieve suitable homogeneity and normality, while plant weight required no transformation. Each harvested pot at a given time represented an independent experimental unit. Measures obtained from technical replicates originating from the same unit were averaged prior to statistical analysis. The SAS Statistical Analysis Software (v. 9.2; SAS Institute, Cary, NC) was used for all analyses.

\section{RESULTS}

Growth promotion of potato plants. Regardless of the presence or absence of S. scabies, treatments with Pseudomonas sp. 
LBUM223 or its isogenic mutant ( $p h z C-)$ significantly increased $(P<0.001)$ total plant weight in 10 -week-old plants (Table 1$)$.

Biological control of common scab. Common scab symptoms were assessed on tubers harvested at weeks 10 and 15 (Fig. 1). The severity of symptoms significantly increased from week 10 to $15(P<0.05)$. At both time points, treatment with Pseudomonas sp. LBUM223 significantly reduced scab symptoms $(P<0.01)$ by $\approx 40$ to $45 \%$ compared with tubers inoculated with $S$. scabies alone or in combination with LBUM223 $\mathrm{phz} C$-. Scab symptoms were also sporadically found on stolons and underground stems when infection was severe (results not shown).

Soil populations of $\boldsymbol{S}$. scabies. Absolute quantification of the txtA gene by qPCR in the geocaulosphere and rhizosphere soil samples enabled the quantification of $S$. scabies cell number. In the rhizosphere, there were no differences in $S$. scabies populations between the different treatments at all times (Fig. 2A). $S$. scabies populations were statistically different at all time points $(P<0.01)$, with populations increasing two- to threefold from week 5 to week 10 and decreasing slightly at week 15 . There was no interaction between time and treatment factors. In the geocaulosphere, treatments with LBUM223 (wild type or mutant) significantly increased $S$. scabies populations $(P<0.05)$, at all times, by approximately twofold (Fig. 2B). There was no significant difference in populations over time and no interaction between time and treatment factors.

Expression of txtA by S. scabies in soil. Geocaulosphere and rhizosphere soil $t x t A$ gene expression values were obtained by dividing total transcript copy numbers detected by RT-qPCR by $S$. scabies cell number determined by qPCR. In the rhizosphere, the application of LBUM223 or LBUM223 phzC- had no effect on txtA expression in S. scabies at all times (Fig. 3A). There was a significant difference in expression values between week 5 and other time points $(P<0.01)$, with the expression at week 5 being generally higher. There was no interaction between time and treatment factors. In the geocaulosphere, when compared with S. scabies alone, the application of the PCA-producing LBUM223 significantly reduced the expression of $t x t A$ by S. scabies $(P<$ 0.005 ), at both 10 and 15 weeks (Fig. 3B), by as much as 6.7-fold at week 15. Inoculation with LBUM223 $\mathrm{phz} C$ - had no effect on $t x t A$ gene expression when compared with the other treatments. There was no significant change in expression over time and no interaction between time and treatment factors.

\section{DISCUSSION}

This study aimed at determining the effect of PCA production by Pseudomonas sp. LBUM223 on potato common scab and its pathogen, $S$. scabies, under soil conditions. Results showed that inoculating potato plants with PCA-producing LBUM223 significantly reduced potato common scab symptoms by almost twofold when compared with plants inoculated with S. scabies alone, whereas inoculation with the LBUM223 isogenic phzC- mutant did not result in any symptom reduction. Therefore, the ability of LBUM223 to produce PCA seems essential in reducing disease development. Quantification of pathogen populations in the rhizosphere and geocaulosphere soils and characterization of the

TABLE 1. Growth-promoting capacity of LBUM223 and LBUM223 phzC-

\begin{tabular}{lc}
\hline Treatment & Total plant weight $(\mathrm{g}) \pm$ SEM $^{z}$ \\
\hline Control & $84.47 \pm 2.64 \mathrm{a}$ \\
LBUM223 phzC- & $103.62 \pm 5.35 \mathrm{~b}$ \\
LBUM223 & $103.98 \pm 4.32 \mathrm{~b}$ \\
Streptomyces scabies & $88.60 \pm 2.19 \mathrm{a}$ \\
S. scabies + LBUM223 phzC- & $100.55 \pm 4.83 \mathrm{~b}$ \\
S. scabies + LBUM223 & $102.84 \pm 5.26 \mathrm{~b}$ \\
\hline
\end{tabular}

${ }^{\mathrm{z}}$ Letters indicate statistically significant differences $(P<0.001)(n=6)$; $\mathrm{SEM}=$ standard error of the mean . expression of txtA, a key biosynthetic gene involved in the production of thaxtomin $\mathrm{A}$, were done to better understand the mechanisms of action potentially involved in common scab disease reduction by LBUM223. Surprisingly, inoculation with LBUM223 (wild type or mutant) increased S. scabies populations in the geocaulosphere, suggesting that PCA production was not acting by antibiosis against the pathogen. The reason for this increase is unknown and needs to be further investigated. However, the presence of the wild-type PCA-producing LBUM223 in the geocaulosphere significantly repressed $t x t A$ expression in $S$. scabies, whereas the LBUM223 isogenic mutant ( $p h z C-$ ) did not. The previous demonstration of a strong correlation existing between txtA expression and thaxtomin production (28) suggests that the decrease in $t x t A$ gene expression observed here could result in a decrease in thaxtomin A production in the geocaulosphere. Because it has previously been shown that a positive relationship exists between the quantity of thaxtomin A produced by $S$. scabies and the severity of common scab symptoms observed (14), the decrease in thaxtomin A production suggested here may account, at least in part, for the reduced symptoms observed when potato plants were treated with PCA-producing LBUM223. This significant difference was only found in the geocaulosphere and not in the rhizosphere. This seems logical considering that the geocaulosphere is adjacent to the tuber surface, the site of action of the pathogen, whereas the roots are generally not affected by common scab.

The mechanism involved in decreasing $t x t A$ gene expression in response to PCA production is not yet characterized and, although many studies have identified molecules that may enhance thaxtomin production, only a few studies have identified repressors of thaxtomin biosynthesis $(2,18)$. It has previously been shown that phenazines are redox molecules capable of interfering with the electron transport chain in different organisms, and there are also some reports of phenazines actively interacting with doublestranded DNA, inhibiting DNA-dependent RNA synthesis to

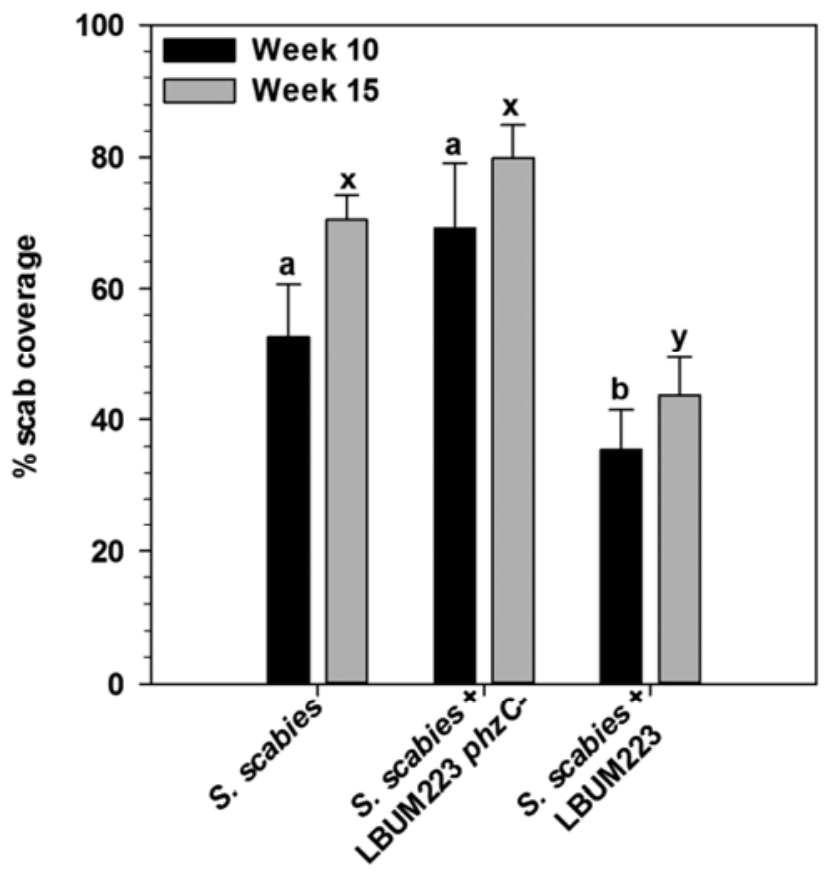

Fig. 1. Tuber disease coverage. Each pot represents an independent experimental unit for which the percentage of scab coverage was averaged for all tubers belonging to the same plant. Values are presented as mean \pm standard error of the mean ( $n=6$ for each treatment at each time). Because an interaction occurred between time and treatment factors, the different treatments were analyzed per time point. Significant differences between treatments are presented $(P<0.01)$ using the letters a and b for week 10 and the letters $\mathrm{x}$ and $\mathrm{y}$ for week 15 . 

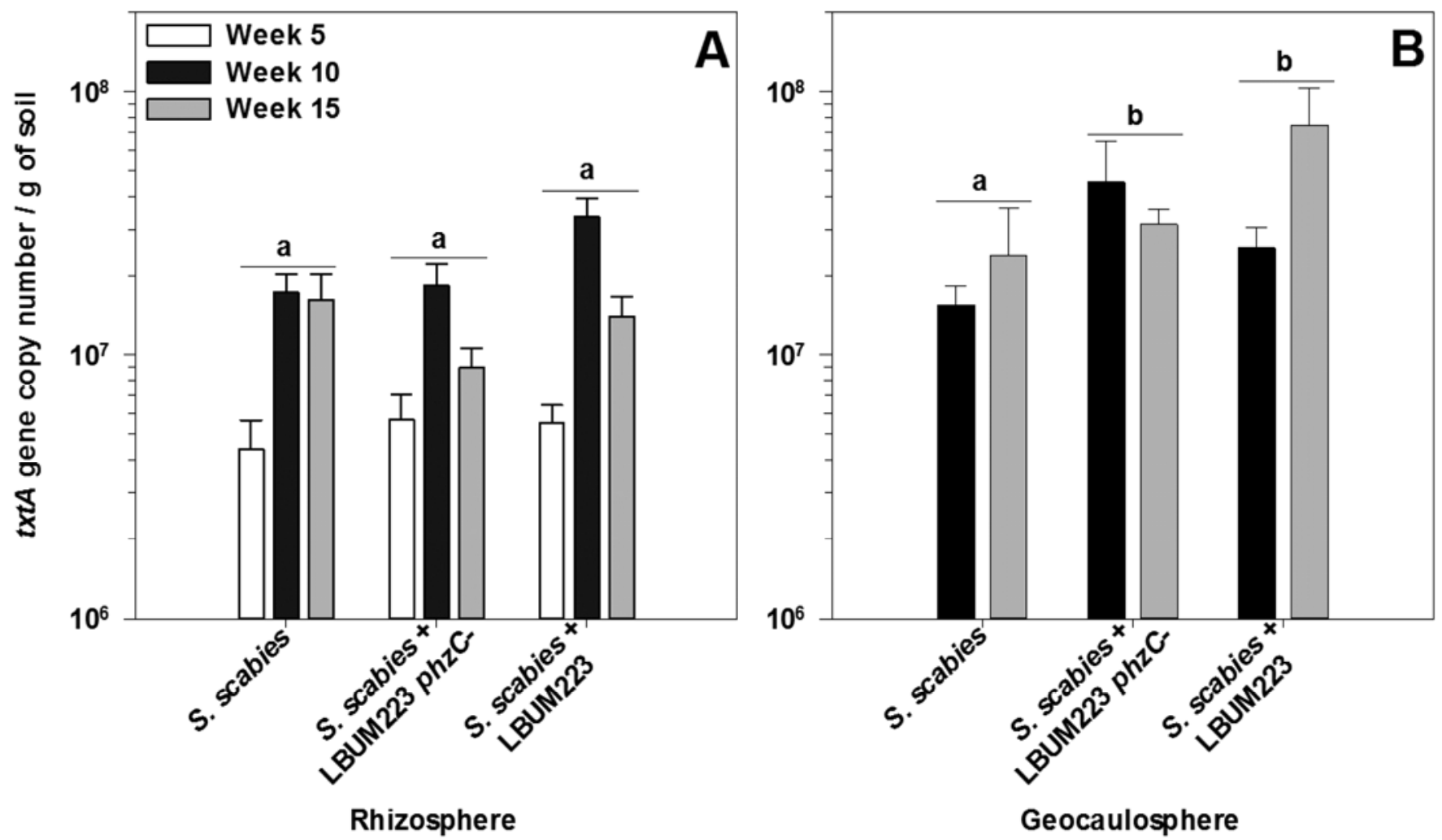

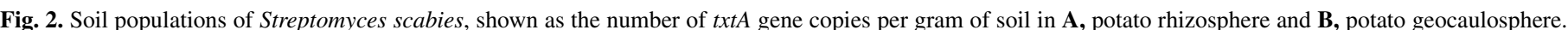

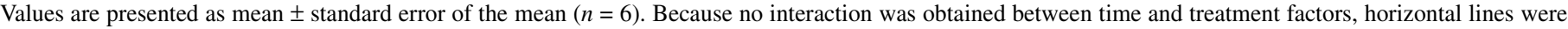

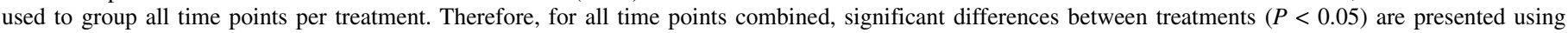
different letters.

varying extents (23). Therefore, it appears logical that PCA might directly affect the expression of genes involved in thaxtomin production but would most probably modify S. scabies' expression profile in a more general manner, altering the expression of numerous genes. This would have to be validated using a transcriptomics approach to determine large-scale changes in gene expression in response to PCA production by LBUM223. Another possibility is that PCA production by LBUM223 may heighten plant defense responses which, in turn, may modulate S. scabies' expression profile. A type of phenazine, pyocyanin, has been shown to elicit an induced systemic resistance (ISR) response in tomato, another solanaceous species (1). The potential of PCA as an ISR elicitor would have to be validated in our current potato system.

In addition to reducing common scab symptoms, Pseudomonas sp. LBUM223 was able to promote plant growth by increasing total plant weight, regardless of its ability to produce PCA. The mechanisms accounting for this growth promotion are currently unknown but may include facilitating nutrient mobilization or the production of growth-inducing phytohormones, such as indole-3acetic acid (30). No increase in total potato yield was observed when disease-free plants were inoculated with LBUM223 (wild type or mutant). Considering that, in this pot experiment, plants were generally limited in the space available for tuber growth, different results may be obtained in a field setting or under other nonrestrictive environmental conditions.

This study is not the first demonstration that antagonistic bacteria can reduce common scab of potato in planta. Greenhouse assays have previously shown that Bacillus sp. Sunhua, producing the antibiotics iturin $\mathrm{A}$ and macrolactin $\mathrm{A}$, was able to significantly reduce the severity of common scab (9), suggesting that the production of different antibiotics may contribute to controlling the disease. A recent study has also assessed the ability of several fluorescent Pseudomonas spp. to control potato common scab in the field in combination with a vermicompost soil amendment (25). In this study, one strain of Pseudomonas mosselii was able to significantly reduce symptoms only when combined with vermicompost. However, the mechanisms involved were not elucidated. Other research groups have also successfully shown common scab disease reduction using nonpathogenic Streptomyces spp. S. diastatochromogenes strain PonSSII and the antagonistic (avirulent) S. scabies strain PonR have been shown to reduce disease symptoms for many years in field-pot trials (20). $S$. melanosporofaciens was also shown capable of reducing symptoms in the field (3). These strains, being of the same genus as the pathogen, have the advantage of niche competition as a mechanism of biocontrol (12) but have the disadvantage of being able to acquire the pathogenicity island responsible for causing the disease through horizontal gene transfer (22).

Among the different groups of antagonistic bacteria that have been studied thus far as potential biocontrol agents against $S$. scabies, each with their advantages and disadvantages, Pseudomonas spp. are of high interest. This is mainly due to their excellent capacity for colonizing the rhizosphere and geocaulosphere, their large nutritional plasticity, and their ease and rapidity of growth under controlled conditions (31). This can positively impact our capacity to formulate, produce, and utilize these organisms at a reasonable cost in an agricultural context.

The underlying mechanisms involved in controlling common scab of potato by PCA-producing Pseudomonas sp. LBUM223 have been partly investigated in this study, and suggest a novel mode of action for PCA, through alteration of the transcriptional activity of at least one key gene required for $S$. scabies pathogenesis. However, this interaction occurring between Pseudomonas sp. LBUM223 and S. scabies in the geocaulosphere will need to be further characterized in order to fully understand what PCA specifically targets in the pathogen that leads to repressing $t x t A$ expression and reducing virulence. 


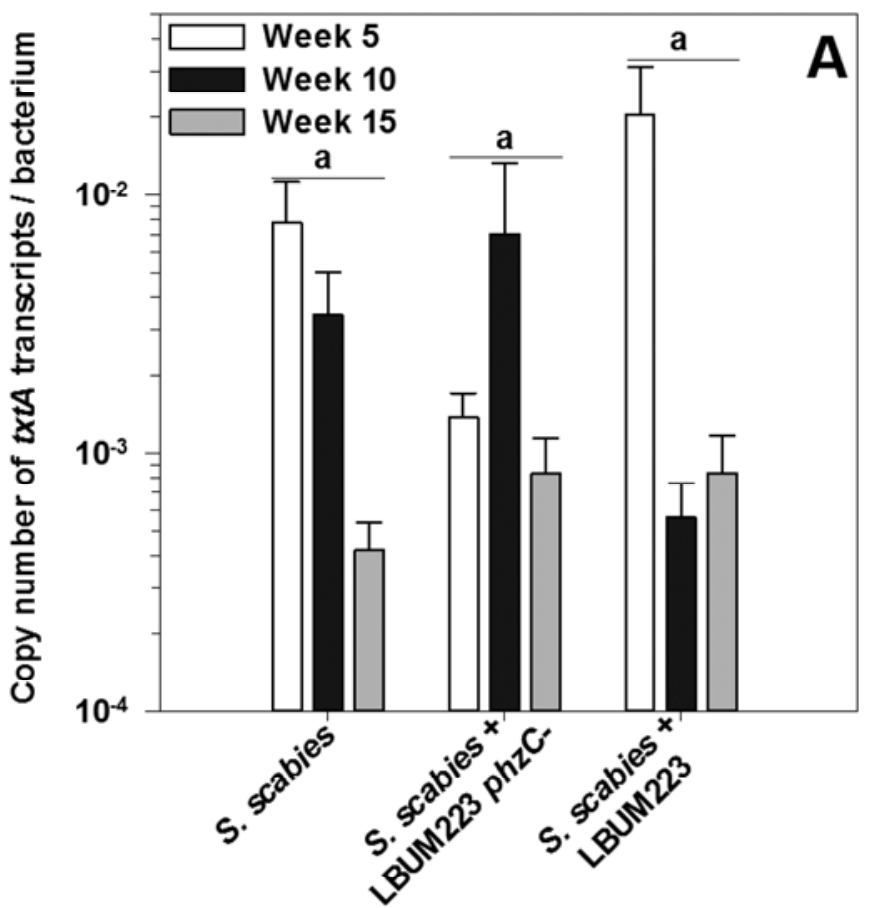

Rhizosphere

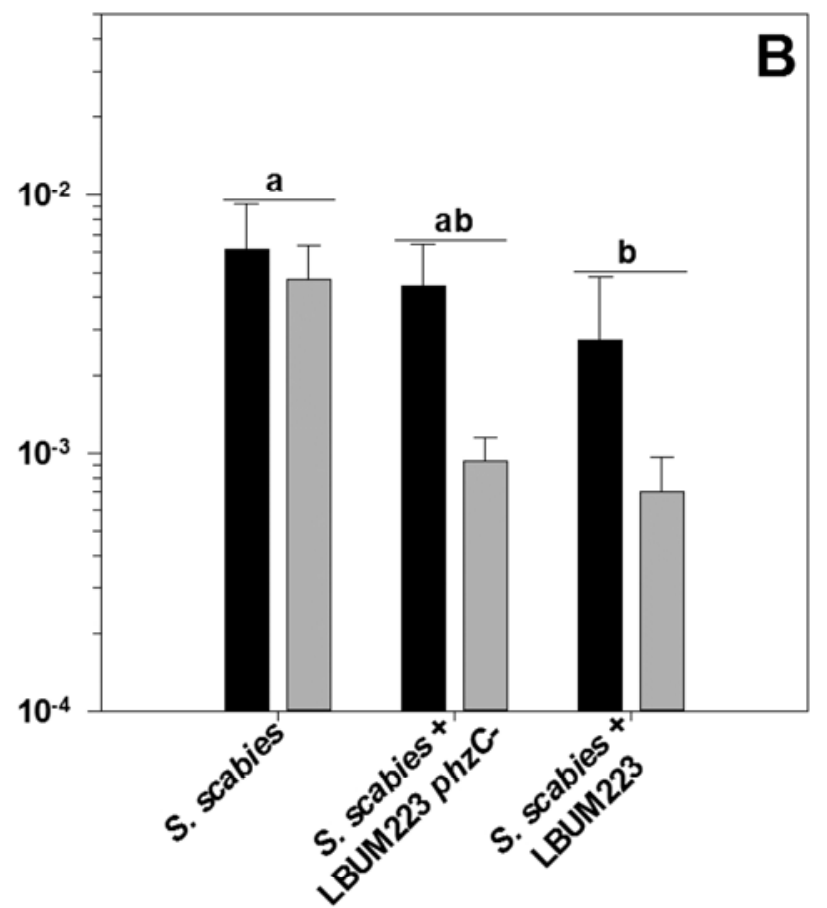

Geocaulosphere

Fig. 3. Expression of txtA by Streptomyces scabies in soil, shown as the total number of txtA transcripts divided by total $S$. scabies cell number in A, potato rhizosphere and $\mathbf{B}$, potato geocaulosphere. Values are presented as mean \pm standard error of the mean $(n=6)$. Because no interaction was obtained between time and treatment factors, horizontal lines were used to group all time points per treatment. Therefore, for all time points combined, significant differences between treatments $(P<0.05)$ are presented using different letters.

\section{ACKNOWLEDGMENTS}

This study was supported by a Natural Sciences and Engineering Research Council (NSERC) and New Brunswick Innovation Foundation grants to M. Filion. A doctoral Alexander Graham Bell Canada Graduate Scholarship (NSERC) was awarded to T. Arseneault. We thank C. Lanteigne and A. Novinscak (Université de Moncton, Moncton, NB, Canada) for their much appreciated technical assistance and G. Moreau (Université de Moncton) for sharing suggestions regarding statistical analyses.

\section{LITERATURE CITED}

1. Audenaert, K., Pattery, T., Cornelis, P., and Höfte, M. 2002. Induction of systemic resistance to Botrytis cinerea in tomato by Pseudomonas aeruginosa 7NSK2: Role of salicylic acid, pyochelin, and pyocyanin. Mol. Plant-Microbe Interact. 15:1147-1156.

2. Babcock, M. J., Eckwall, E. C., and Schottel, J. L. 1993. Production and regulation of potato-scab-inducing phytotoxins by Streptomyces scabies. J. Gen. Microbiol. 139:1579-1586.

3. Beauséjour, J., Clermont, N., and Beaulieu, C. 2003. Effect of Streptomyces melanosporofaciens strain EF-76 and of chitosan on common scab of potato. Plant Soil 256:463-468.

4. Bürgmann, H., Widmer, F., Sigler, W. V., and Zeyer, J. 2003. mRNA extraction and reverse transcription-PCR protocol for detection of nifH gene expression by Azotobacter vinelandii in soil. Appl. Environ. Microbiol. 69:1928-1935.

5. Chin-A-Woeng, T. F. C., Bloemberg, G. V., and Lugtenberg, B. J. J. 2003. Phenazines and their role in biocontrol by Pseudomonas bacteria. New Phytol. 157:503-523.

6. Decoste, N. J., Gadkar, V. J., and Filion, M. 2010. Verticillium dahliae alters Pseudomonas spp. populations and HCN gene expression in the rhizosphere of strawberry. Can. J. Microbiol. 56:906-915.

7. Fry, B. A., and Loria, R. 2002. Thaxtomin A: Evidence for a plant cell wall target. Physiol. Mol. Plant Pathol. 60:1-8.

8. Haas, D., and Défago, G. 2005. Biological control of soil-borne pathogens by fluorescent pseudomonads. Nat. Rev. Microbiol. 3:307-319.

9. Han, J. S., Cheng, J. H., Yoon, T. M., Song, J., Rajkarnikar, A., Kim, W. G., Yoo, I. D., Yang, Y. Y., and Suh, J. W. 2005. Biological control agent of common scab disease by antagonistic strain Bacillus sp. sunhua. J. Appl. Microbiol. 99:213-221.
10. Haynes, K. G., Christ, B. J., Burkhart, C. R., and Vinyard, B. T. 2009. Heritability of resistance to common scab in diploid potatoes. Am. J. Potato Res. 86:165-170.

11. Healy, F. G., Krasnoff, S. B., Wach, M., Gibson, D. M., and Loria, R. 2002. Involvement of a cytochrome P450 monooxygenase in thaxtomin A biosynthesis by Streptomyces acidiscabies. J. Bacteriol. 184:2019-2029.

12. Hiltunen, L. H., Ojanperä, T., Kortemaa, H., Richter, E., Lehtonen, M. J., and Valkonen, J. P. T. 2009. Interactions and biocontrol of pathogenic Streptomyces strains co-occurring in potato scab lesions. J. Appl. Microbiol. 106:199-212.

13. Johnson, E. G., Joshi, M. V., Gibson, D. M., and Loria, R. 2007. Cellooligosaccharides released from host plants induce pathogenicity in scabcausing Streptomyces species. Physiol. Mol. Plant Pathol. 71:18-25.

14. Kinkel, L. L., Bowers, J. H., Shimizu, K., Neeno-Eckwall, E. C., and Schottel, J. L. 1998. Quantitative relationships among thaxtomin A production, potato scab severity, and fatty acid composition in Streptomyces. Can. J. Microbiol. 44:768-776.

15. Kloepper, J. W., Schroth, M. N., and Miller, T. D. 1980. Effects of rhizosphere colonization by plant growth-promoting rhizobacteria on potato plant development and yield. Phytopathology 70:1078-1082.

16. Lambert, D. H., and Loria, R. 1989. Streptomyces scabies sp. nov., nom. rev. Int. J. Syst. Bacteriol. 39:387-392.

17. Lawrence, C. H., Clark, M. C., and King, R. R. 1990. Induction of common scab symptoms in aseptically cultured potato tubers by the vivotoxin, thaxtomin. Phytopathology 80:606-608.

18. Legault, G. S., Lerat, S., Nicolas, P., and Beaulieu, C. 2011. Tryptophan regulates thaxtomin A and indole-3-acetic acid production in Streptomyces scabiei and modifies its interactions with radish seedlings. Phytopathology 101:1045-1051.

19. Lerat, S., Simao-Beaunoir, A.-M., Wu, R., Beaudoin, N., and Beaulieu, C. 2010. Involvement of the plant polymer suberin and the disaccharide cellobiose in triggering thaxtomin A biosynthesis, a phytotoxin produced by the pathogenic agent Streptomyces scabies. Phytopathology 100:91-96.

20. Liu, D., Anderson, N. A., and Kinkel, L. L. 1995. Biological control of potato scab in the field with antagonistic Streptomyces scabies. Phytopathology 85:827-831.

21. Loria, R., Bignell, D. R. D., Moll, S., Huguet-Tapia, J. C., Joshi, M. V., Johnson, E. G., Seipke, R. F., and Gibson, D. M. 2008. Thaxtomin biosynthesis: The path to plant pathogenicity in the genus Streptomyces. Antonie Leeuwenhoek 94:3-10.

22. Loria, R., Kers, J., and Joshi, M. 2006. Evolution of plant pathogenicity in Streptomyces. Annu. Rev. Phytopathol. 44:469-487. 
23. Mavrodi, D. V., Blankenfeldt, W., and Thomashow, L. S. 2006. Phenazine compounds in fluorescent Pseudomonas spp. biosynthesis and regulation. Annu. Rev. Phytopathol. 44:417-445.

24. Paulin, M. M., Novinscak, A., St-Arnaud, M., Goyer, C., DeCoste, N. J., Privé, J.-P., Owen, J., and Filion, M. 2009. Transcriptional activity of antifungal metabolite-encoding genes phlD and hcnBC in Pseudomonas spp. using qRT-PCR. FEMS Microbiol. Ecol. 68:212-222.

25. Singhai, P. K., Sarma, B. K., and Srivastava, J. S. 2011. Biological management of common scab of potato through Pseudomonas species and vermicompost. Biol. Control 57:150-157.

26. St-Onge, R., Gadkar, V. J., Arseneault, T., Goyer, C., and Filion, M. 2011. The ability of Pseudomonas sp. LBUM 223 to produce phenazine1-carboxylic acid affects the growth of Streptomyces scabies, the expression of thaxtomin biosynthesis genes and the biological control potential against common scab of potato. FEMS Microbiol. Ecol. 75:173183.

27. St-Onge, R., Goyer, C., Coffin, R., and Filion, M. 2008. Genetic diversity of Streptomyces spp. causing common scab of potato in eastern Canada. Syst. Appl. Microbiol. 31:474-484.

28. St-Onge, R., Goyer, C., and Filion, M. 2010. Pseudomonas Spp. can inhibit Streptomyces scabies growth and repress the expression of genes involved in pathogenesis. J. Bacteriol. Parasitol. 1:101. doi:10.4172/21559597.1000101

29. Turnbull, A. L., Liu, Y., and Lazarovits, G. 2012. Isolation of bacteria from the rhizosphere and rhizoplane of potato (Solanum tuberosum) grown in two distinct soils using semi selective media and characterization of their biological properties. Am. J. Potato Res. 89:294305 .

30. Vessey, J. K. 2003. Plant growth promoting rhizobacteria as biofertilizers. Plant Soil 255:571-586.

31. Weller, D. M. 2007. Pseudomonas biocontrol agents of soilborne pathogens: Looking back over 30 years. Phytopathology 97:250-256.

32. Whipps, J. M. 2001. Microbial interactions and biocontrol in the rhizosphere. J. Exp. Bot. 52:487-511. 